\title{
Study on the Application of 6S Lean Management to the Literacy Training of Clothing Professionals
}

\author{
WU Yujun \\ Institute of Clothing Technology, Chengdu Textile College, Chengdu 611731, Sichuan, China
}

Keywords: 6S Lean Management; Professional Literacy; Clothing Specialty

\begin{abstract}
By unscrambling the soft power of vocational education, the idea that the literacy training of professionals is a combination of the concept of 6S lean management with teaching practice is raised in this paper according to the integration of $6 \mathrm{~S}$ lean management with clothing professionals in clothing enterprises, for promoting the teaching in vocational schools to adapt to the needs of enterprises for talents.
\end{abstract}

\section{Introduction}

Training high-quality workers to fit with course contents and professional standards and letting the teaching process to accord with the production process are major issues discussed in the decision of the State Council on accelerating the development of the modern vocational education. Professional standards incorporate the professional literacy of personnel; the production process contains the specialty accomplishment of personnel. That is to say, the improvement of professional vocational skills has to meet the industrial requirements, but also the improvement of professional literacy has to accord with the professional requirements. How to train personnel and increase the personnel literacy is an important project in improving the soft power of domestic enterprises. How to train students and increase student's professional literacy is an important task in improving the soft power of clothing vocational education. Vocational college graduates usually cannot adapt to the working environment during enterprise internship; enterprises often have excuses for the shortcomings of the professional literacy of new employees. For this reason, a study direction is raised for the adaptability between vocational education and corporate culture and the target of literacy training.

\section{Demands of Clothing Enterprises for the Literacy of Professionals}

Recently, a questionnaire survey on basic qualities was made by several companies, including the qualities in five aspects (professional cultivation, basic knowledge, management skills, business skills, and EQ cultivation), of which basic knowledge, management skills, and EQ cultivation were surveyed independently; the items of professional cultivation and business skills were numerous, and therefore the two aspects were not specifically segmented. The result found that "professional cultivation" and "EQ cultivation" were more important than "knowledge and skills".

In the five basic qualities, each item required respondents to choose according to the importance degree; the weighted statistical analysis showed that "professional cultivation" ranked first, accounting for 23.77\%; "EQ cultivation" ranked second, accounting for 22.56\%; "management skills" ranked third, accounting for 18.85\%; "business skills" ranked fourth, accounting for 17.46\%; "basic knowledge" ranked last, accounting for 17.36\%. Visibly, "professional cultivation" and "EQ cultivation" were more important than "skills and knowledge". Another issue deserving concerns was that "basic knowledge" unexpectedly ranked last, suggesting the traditional educational model centered on conveying knowledge faced great challenges.

Personnel expected by clothing enterprises were the talents who not only possessed excellent professional knowledge and skills, but also could blend with the mainstream management culture of enterprises. "6S management" methods were applied by many large and medium-sized clothing enterprises during enterprise reform and transformation. "6S management", expanded from Japanese enterprises' 5S, is a feasible field management idea and method in modern factories, and briefly 
refers to Seiri, Seiton, Seiso, Seiketsu, Shitsuke, and Safety; its roles are to improve the efficiency, ensure the quality and make the working environment clean and orderly, in which top priority is given to prevention for the ultimate goal of safety assurances. To fully implement the above six points, persistent style of work and rigorous attitude and sense of responsibility toward work are required; learning attitude affects the working attitude. The personnel demanded by enterprises are employees fit with corporate management culture. Therefore, the professional literacy training for students can be started from corporate management culture.

\section{Problems in the current students majoring in fashion design}

The graduation of the students majoring in fashion design is also a transition from study to work when they are becoming new corporate employees. In this stage, their behavioral habits will quickly match and adapt to corporate management; from training rooms to production sites, the original problems may inevitably be exposed to the working process of enterprises. Practical training course in fashion design program is taken for example: a large amount of skills training forces teachers to focus on clothing technology teaching, but ignore the training of student's professional literacy. In some practical training rooms, it was obvious that personal articles were randomly placed on the working tables; semi-finished and finished clothing products were carelessly piled up; cutting wastes were discarded disorderly; the table-boards of equipment were very dirty; the workings sites were really dirty, disorderly and bad. Students' headgear and footwear were also random; some students hand down loosely their long hair, and even were heavily powdered on the face. All these were not the reasonable professional images in the production workshops. The courses in fashion design program include many practice courses, requiring a variety of tools and materials; students fail to form good, effective management habits in pre-class preparation, in-class management, and after-class reviews, and often encounter many problems in details. All these are shortcomings discovered by enterprises while employing fashion design graduates, exposing the ignorance to the details in the process of teaching.

\section{Effectiveness of 6S on Personnel Training}

Why do enterprises promote "6S management"? This must be a result of effective practices in many years. 6S management is 6S lean management, which is the management foundation of many clothing enterprises and requires employees to develop standardization as a habit and let it become a natural instinct reaction. Similarly, 6S lean management is the management foundation of the teaching in fashion design program: students are required to develop standardization as a habit and let it become a natural instinct reaction. "Seiri, Seiton, Seiso, Seiketsu, Shitsuke, and Safety" is a method for both production site management and field training management. Whether the practical training classes of students can closely join with the production sites of enterprises requires the establishment of an equivalent bridge from the management method. The stage of higher vocational education is a bridge for students to go onto work. In this period, students need to early cultivate professional literacy; 6S lean management can be introduced to practical teaching and management for achieving the deep integration between higher vocational education and enterprises, so that students can gradually adapt to the role of enterprise employees.

Seiri. Any articles in learning sites and living sites are divided into the necessary and the unnecessary; everything except the unnecessary is abandoned, for the purpose of making room, flexibly using the space, preventing misuse, and building up a relaxed learning space. It is necessary to make early preparations for learning materials and tools, so that students can keep a complete and stable state of mind to adapt to the new learning contents.

Seiton.There are many different kinds of clothing material tools, and therefore the carrying management requires meticulous patience. Through seiton, the tools, books and materials required by learning are orderly placed and labelled according to the provided positions, aiming to let the learning sites clear at a glance and save the time of looking for items; in a neat working environment, the 
elimination of excessive overstocks can effectively reduce wastes and save cost. Meanwhile, students are promoted to develop a serious attitude toward ever tiny thing in work and study, and then make full use of class hours to complete skills training and improve learning efficiency.

Seiso. All places in learning sites are cleaned up for keeping a clean and beautiful environment. Especially for the cleaning of equipment, the damage and pollution in the clothing making process are mainly derived from equipment dirt. Only if the cleaning work is detailed, the quality of finished clothing products will be stabilized, and also the injuries in training will be reduced.

Seiketsu. Seiketsu includes not only work and study places, but also students' dress-up and image and the finished clothing products. Clothing is a reflection to the outer beauty, but also a construction for positive image; clean and neat appearance can leave a good impression in the mind of people. Clothing is cored at quality; the serious attitude toward quality needs to be trained from beginners; clean clothing appearance can show a positive recognition on the professional ability in terms of image, and this is also a major aspect for the professional literacy of students to get trusted.

Shitsuke. Each student develops good study habits, follows the rules, and cultivates an active spirit (also known as habituation). The purpose is to train the corporate back-up employees with good habits and following rules and build up an excellent team spirit.

Safety. Students' safety education is emphasized; a concept of safety first is always in the mind of students for preventing all possible hidden dangers. The safety of electricity use and various clothing equipment is emphasized. The purpose is to establish a safe production environment; all the work should proceed under the premise of safety.

With the implementation of "6S management", completely different study attitudes and styles will be fundamentally formed; the overall environment of the production practices will be changed. In clothing production practice site (before 6S management) as shown in Fig.1 and clothing production practice site (after 6S management) as shown in Fig.2, two totally distinct production environments would be formed.

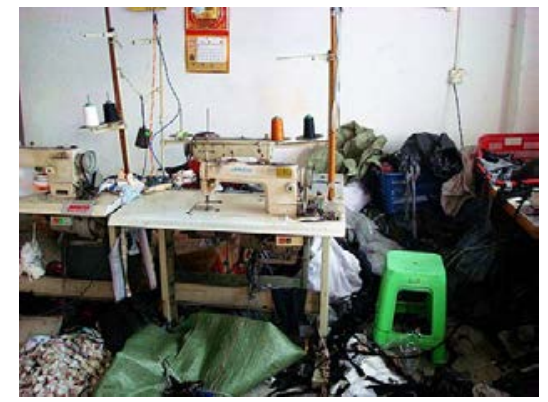

Fig. 1 clothing production practice site (before 6S management)

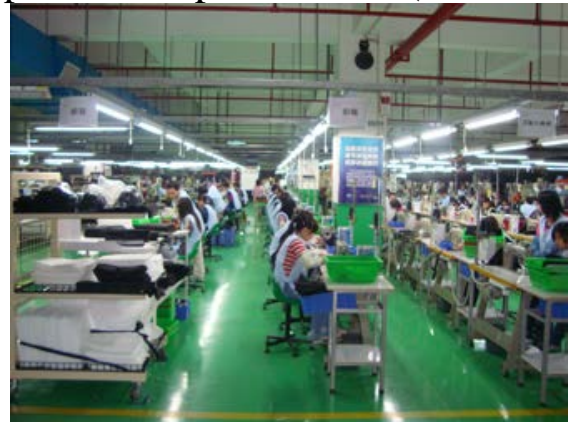

Fig.2 clothing production practice site (after 6S management)

\section{The Application of 6S Lean Management to Teaching Practice}

The key point of 6S lean management lies in standardization. The so-called standardization means making an optimal standard and then continuously replicating it, in order to let the operating costs minimized and the team strength maximized. Corporate operation relies on the fights of teams-it is never like a business man to manage his own business alone. Thus, standardization is of vital importance to an enterprise. The teaching practice in fashion design program is usually conducted by 
class-based groups, and mostly divided into two types: (1) independent production for varieties; (2) batch production line training. The first focuses on personal management, while the second is centered on team management. Personal management is a start of training students to behavior themselves first; team management can show the overall effectiveness of personal management which achieves the standards. Clothing technology standard is a quality control standard; a specification process can grasp the realization of every detail.

The essence of $6 \mathrm{~S}$ lean management lies in the standardization of personnel and the crystallization of things. The literacy of fashion professionals is trained in every detail of study and work and how to achieve the standardized operation, improve the process details and finished clothing products, and build up good professional images and so on. The application of 6S lean management seems to be a site management, but actually is the management of teaching activities and the training of professional literacy in a profound sense. For teachers, regulating the behavior of students is to further standardize the ideas of students. How to more professionally and effectively practice teaching activities and make reasonable use of $6 \mathrm{~S}$ teaching management ways is a direction necessary for teachers of different programs to consider by combining with teaching contents and purposes.

\section{Conclusion}

In the teaching of fashion design program, all kinds of problems were discovered. The feedback information from the employing units also presented the pities for every aspect of professional personnel training. The solutions to be sought were various. However, $6 \mathrm{~S}$ lean management applied by enterprises in production management to combine with teaching management has not been largely popularized and implemented; the application of $6 \mathrm{~S}$ lean management in teaching is an important guarantee for standardizing the professional teaching activities and effectively improving the literacy of professionals. When 6S lean management becomes an important method of the practice teaching management in clothing program, it will play an unexpected effect on the training of fashion professionals.

\section{References}

[1] ZHU Huaping. Discussion and Practice on the Practice Training Base Management of Secondary Vocational Education - the Permeation of 6S Lean Management Concept in Clothing Enterprises [J]. Guangxi Education, 2010 (33): 120-122.

[2] ZHENG Jing. Discussion on the Application of 6S Lean Management Method in Secondary Vocational Experiments and Practical Teaching [J]. Journal of Chemical Industry of Jiangxi Province, 2014 (1): 265-266.

[3] MIAO Lingyu. Discussion on the Hierarchical Training Teaching of 6S Management Based Vocational Colleges [J]. Journal of Liaoning Vocational College, 2013 (8): 72-73.

[4] REN Lihui. Study on the Application of 5S Management to the Transformation of Traditional Clothing Enterprises [J]. China’s Market, 2014 (21): 68-69.

[5] LIU Aihua. Promoting 6S Management and Improving the Professional Literacy of the Students in Training Management [D]. Management \& Technology of SME, 2014 (10): 283-284.

[6] WANG Haiyan. The Application of 6S Site Management to Clothing Factory A [D]. Heilongjiang: Northeast Agricultural University, 2013: 20 22.

[7] GE Yan, FU Haihong, WANG Fangfang. Exploration on the Integrated Personnel Training Model of Fashion Program based on Enterprise Needs [J]. Journal of Textile Science and Technology Progress, 2014 (3): 90-91. 


\section{Introduction to the Author}

WU Yujun (1980- ), female, born in Chengdu, Sichuan province, attaining a master degree, is a college lecturer now. She is dedicated to studying clothing engineering. 